\title{
Synthesis of Ag-doped hydrogenated carbon thin films by a hybrid PVD-PECVD deposition process
}

\author{
MAJJI VENKATESH ${ }^{a}$, SUKRU TAKTAK ${ }^{b, *}$ and EFSTATHIOS I MELETIS ${ }^{\mathrm{a}}$ \\ ${ }^{a}$ Department of Materials Science and Engineering, Faculty of Engineering, University of Texas at Arlington, \\ Arlington, TX 76019, USA \\ ${ }^{\mathrm{b}}$ Department of Metallurgical and Materials Engineering, Faculty of Technology, Afyon Kocatepe University, \\ Afyonkarahisar 03200, Turkey
}

MS received 29 November 2013; revised 6 February 2014

\begin{abstract}
Silver-doped hydrogenated amorphous carbon (Ag-DLC) films were deposited on Si substrates using a hybrid plasma vapour deposition-plasma enhanced chemical vapour deposition (PVD-PECVD) process combining Ag target magnetron sputtering and PECVD in an $\mathrm{Ar}-\mathrm{CH}_{4}$ plasma. Processing parameters (working pressure, $\mathrm{CH}_{4} / \mathrm{Ar}$ ratio and magnetron current) were varied to obtain good deposition rate and a wide variety of Ag films. Structure and bonding environment of the films were obtained from transmission electron microscopy (TEM), energy dispersive spectroscopy (EDS) and Fourier transform infrared (FTIR) spectroscopy studies. Variation of processing parameters was found to produce Ag-doped amorphous carbon or diamond-like carbon (DLC) films with a range of characteristics with $\mathrm{CH}_{4} / \mathrm{Ar}$ ratio exercising a dominant effect. It was pointed out that Ag concentration and deposition rate of the film increased with the increase in d.c. magnetron current. At higher Ar concentration in plasma, Ag content increased whereas deposition rate of the film decreased. FTIR study showed that the films contained a significant amount of hydrogen and, as a result of an increase in the Ag content in the hydrogenated DLC film, $s p^{2}$ bond content also increased. The TEM cross sectional studies revealed that crystalline Ag particles were formed with a size in the range of $2-4 \mathrm{~nm}$ throughout an amorphous DLC matrix.
\end{abstract}

Keywords. Amorphous carbon; FTIR analysis; silver; hybrid deposition; hydrogenated DLC.

\section{Introduction}

Nanostructured materials can exhibit unique mechanical, chemical and electronic properties and thus possess a great potential for applications in tribology, electronics, biotechnology and information technology (Wang et al 1998). The tribological behaviour is mainly dependent on surface characteristics of the materials. Nanocomposite films have a tremendous potential to modify and tailor the surface state, and optimize wear and frictional behaviour of the materials while maintaining desirable bulk material properties such as strength and toughness (Bull 1995).

During the past two decades, amorphous carbon or diamond-like carbon (DLC) films have attracted an overwhelming interest from both industry and the research community. DLC films offer a wide range of exceptional physical, mechanical, biomedical and tribological properties. Hydrogenated DLC films are characterized as amorphous and consist of a mixture of diamond-like and graphitelike domains. They are usually referred to as a-C:H films. The diamond-like character that gives high hardness to DLC films comes from the $s p^{3}$ bonding of $\mathrm{C}$ atoms, whereas the $s p^{2}$ bonding gives the graphite-like behaviour

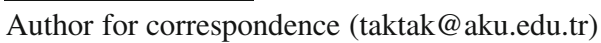

such as low coefficient of friction (Robertson 1992). Tribological behaviour of DLC films strongly depends on both the nature of the coating and test conditions including applied load, speed, environment and contact temperature and interfacial chemistry parameters (Erdemir and Donnet 2006).

The addition of metal atoms in the carbon matrix causes great changes in chemical and tribological properties of DLC coatings and such metal alloyed coatings are often denoted as Me-DLCs. In Me-DLC composite films containing metal such as $\mathrm{Cu}$ or $\mathrm{Ag}$ inert with respect to carbon, interatomic forces in crystallite-carbon interfaces can be weak. These films may have low internal stress, high ductility and toughness. In other words, the tribological behaviour and friction properties of these Me-DLC composite films such as $\mathrm{Cu}-\mathrm{C}$ or $\mathrm{Ag}-\mathrm{C}$ films can be very distinct from those of carbide forming Me-DLC composite films (Pauleau and Thiery 2004; Hussain and Pal 2006). Recently, DLC-metal composite coatings, especially Ag-DLC, have gained increasing attention as a new area of DLC research. Ag-DLC composite films can be used in optical device applications (Ahmed et al 2009), cardiovascular devices or implants due to the surface anti-bacterial properties (Kwok et al 2007; Baba et al 2013; Lan et al 2013), of space devices due to wear resistance against oxygen plasma etching (Marciano et al 2008), for low-threshold field emitter application (Ahmed et al 2008), 
electrodes in electrochemical analysis in microelectromechanical systems (Lee and Ting 2003) and tribological applications (Liu and Meletis 1997; Manninen et al 2013; Takeno et al 2013).

Me-DLC films have been synthesized by different deposition methods, thereby providing a wide range of different film properties. Yu et al (2009) studied non-hydrogenated Ag-DLC films prepared by a mid-frequency dual-magnetron system and they investigated influence of $\mathrm{Ag}$ content and grain size on microstructure. They found that the $\mathrm{Ag}$ nanocrystallites were dispersed in the DLC matrix, and increasing $\mathrm{Ag}$ content resulted in an increase of the $\mathrm{Ag}$ nano size. Paul et al (2009) synthesized silver/DLC composite films by capacitively coupled plasma (CCP) chemical vapour deposition (CVD) technique. They reported that silver nanocryatallite size increased from $10 \mathrm{~nm}$ to $36 \mathrm{~nm}$ for films deposited with increasing amount of silver in the DLC matrix. Choi et al (2007) reported that Ag atoms into DLC films, deposited by hybrid ion beam deposition system (an end-Hall-type ion gun and d.c. magnetron sputtering), played a critical role due to the weak bond between $\mathrm{C}$ and $\mathrm{Ag}$ atoms resulting in the reduction of the residual stress.

During the synthesis of metal-doped hydrogenated DLC, working pressure, magnetron current and concentration of gaseous species in the plasma play a critical role because they all affect the properties and thickness of the film. In the present investigation, the effect of three major PVD/PECVD processing parameters was studied. Ag-DLC films synthesized by combining d.c. plasma enhanced chemical vapour deposition (PECVD) and d.c. magnetron sputtering of $\mathrm{Ag}$ target at different gas mixtures, magnetron current and working pressures. The films, which had a regular increment of Ag content and good deposition rate, were characterized using Fourier transform infrared (FTIR) spectroscopy and high-resolution transmission electron microscopy.

\section{Experimental}

All thin films were deposited on Si (100) wafers with an area of $2 \mathrm{~cm}^{2}$. Prior to deposition, the wafers were cleaned in acetone and then cleaned with compressed air. The hybrid PVD/PECVD deposition system, which has been used for the synthesis of Ag-DLC, is seen in figure 1. The chamber was roughed down to 20 mTorr using the mechanical pump, and then the chamber was exposed to the cryopump by opening the gate valve. The base pressure of the chamber was around $2.5 \times 10^{-6}$ Torr. The chamber was purged two times with Argon prior to any processing. The substrate was sputtered cleaned with Argon at a bias of $-1000 \mathrm{~V}$ for $10 \mathrm{~min}$ at a pressure of $30 \mathrm{mTorr}$. Sputter cleaning removes any surface contamination and contributes to good adhesion of the films.

Hydrogenated Ag-DLC films were deposited by d.c. sputtering of $\mathrm{Ag}$ with a $\mathrm{CH}_{4} / \mathrm{Ar}$ mixture for a d.c. negative bias $(-1000 \mathrm{~V})$ during 30 and $60 \mathrm{~min}$. Ag was initially presputtered on the shutter plate to establish a good plasma, and the shutter was opened when a proper plasma was

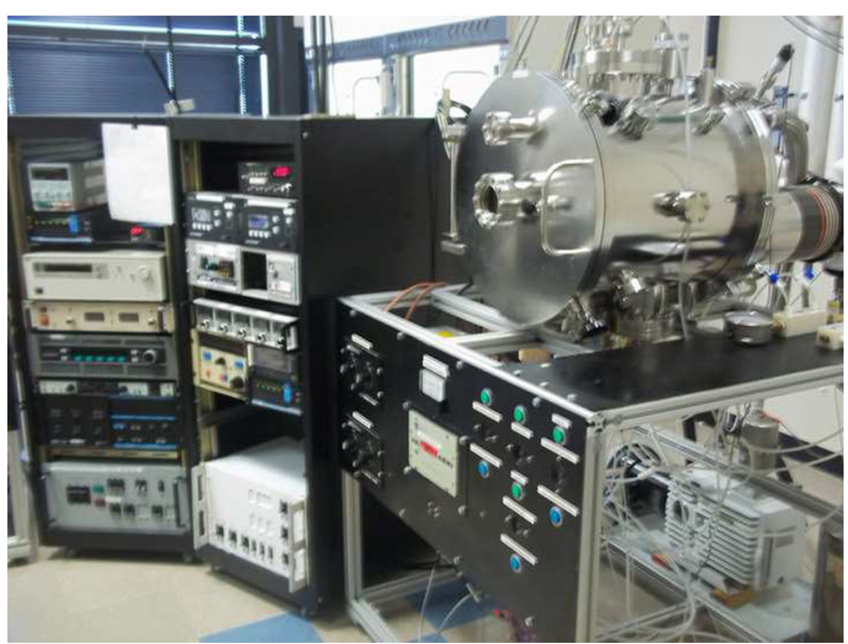

Figure 1. Hybrid PVD/PECVD deposition system.

established. The working pressure (20, 30 and $40 \mathrm{mTorr})$, $\mathrm{CH}_{4} / \mathrm{Ar}$ ratio (10/90-30/70) and magnetron current (30$100 \mathrm{~mA}$ ) were varied to obtain good deposition rate and a wide variety of $\mathrm{Ag}$ films. Pure DLC films were also prepared using the hydrocarbon ion beam without operating the sputter gun. Two small areas on the opposite sides of each sample were masked both to prevent deposition and to allow film thickness measurement. The surface optical profilometer (WYKO NT 1000), which functions on the principle of light interference at a magnification of $10 \mathrm{X}$, traverses on the masked area and measures the height difference. At least twelve measurements were performed for each masked area, and the average values of the film thickness were reported. The deposition rate of Ag-DLC films was estimated by the ratio of the observed thickness to the total deposition time. Scanning Electron Microscopy (JEOL JSM 6100) in conjunction with Energy Dispersive Spectroscopy (Oxford, model 7582) system was used to obtain the composition of the Ag-DLC films (Ag, C). The samples were analyzed at an acceleration voltage of $20 \mathrm{keV}$. EDS analysis values signified the average of at least twelve measurements.

The investigation of $\mathrm{C}-\mathrm{H}$ bonding in the DLC and $\mathrm{Ag}$ DLC films (Ag-DLC30-3, Ag-DLC30-7, Ag-DLC30-9, AgDLC30-10 and Ag-DLC30-11) was performed by FTIR spectroscopy (Nicolet) in the range $2800-3150 \mathrm{~cm}^{-1}$ which reveals a high $\mathrm{H}$ content in the films. The spectrum of the films was subtracted from the $\mathrm{Si}$ wafer background to obtain the absorbance response of the films. The resultant curve was smoothed twice using a 25 point smoothing in the OMNIC software. The region for $\mathrm{C}-\mathrm{H}$ stretching was selected and subjected to a base line correction. The corrected curve was subjected to Fourier self deconvolution to get the component peaks. Deconvolution of the spectra was performed using Gaussian distribution to calculate the $\mathrm{C}-\mathrm{H}$ $s p^{3} /\left(s p^{2}+s p^{3}\right)$ ratio. HRTEM of Ag-DLC samples was performed on Hitachi H-9500 HRTEM operated at $300 \mathrm{keV}$ with a point-to-point resolution of $0.18 \mathrm{~nm}$. 


\section{Results and discussion}

\subsection{Synthesis of Ag-doped hydrogenated DLC thin films}

A series of experiments were performed to obtain a varying Ag content in DLC. The deposition parameters, obtained film thickness, deposition rate and Ag content of Ag-DLC thin films for $-1000 \mathrm{~V}$ bias voltages are given in table 1 . It was observed that the working pressure and $\mathrm{CH}_{4} / \mathrm{Ar}$ ratio played a very important role for controlling the Ag content in DLC. As seen in table 1, silver was obtained in the DLC up to 8.6 at $\%$ at $100 \mathrm{~mA}$ target current and $10 / 90$ of $\mathrm{CH}_{4} / \mathrm{Ar}$ ratio for 30 mTorr working pressure. The films obtained in this working pressure had a uniform colour and appearance. In the case of 20 mTorr working pressure, the film quality was not good (not uniform colour) and adherent to substrate although higher Ag content was found 10.28 and 13.7 at $\%$ for $\mathrm{CH}_{4} / \mathrm{Ar}$ ratios of $15 / 85$ and $10 / 90$, respectively. The deposition rate changed with the percentage of $\mathrm{CH}_{4}$, and the highest deposition rate value was found for $30 \% \mathrm{CH}_{4}$.

Figure 2 shows the effect of methane flow in the gas mixture composed of $\mathrm{Ar}$ and methane on deposition rate and $\mathrm{Ag}$ content in the DLC for 40, 30 and 20 mTorr working pressures and $-1000 \mathrm{~V}$ bias voltages. Although Ar gas ratio was increased to $90 \%$, very little silver could be found in the DLC because of a significant poisoning of the target for the samples carried out at 40 mTorr. As seen in figure 2(b), the Ag content in the hydrogenated DLC decreased with an increase in methane flow in the gas mixture. However, the deposition rate of nanocomposite DLC increased with an increase in methane flow percentage. When the Ar concentration was less than $90 \%$, the incorporation of $\mathrm{Ag}$ in the DLC film was detected slightly. This was probably due to a significant poisoning of the target caused by the high flux of carbon ions that decreases the sputtering yield of the silver target. Similar target poisoning observations were reported for metal incorporated DLC films synthesized in various deposition systems (Bewilogua et al 2000; Choi et al 2008a, b; Wang et al 2011).

As the $\mathrm{CH}_{4}$ flow decreased, the silver content in the DLC increased and the deposition rate decreased at 20 mTorr (figure 2c). As seen in figure 2(c), the deposition rates of the films coated with $10 \%$ and $15 \%$ methane flows were higher than that of films coated with $20 \%$ methane flow. This can be attributed to a higher silver content of the samples treated in $10 \%$ and $15 \%$ methane flow ratios. It was reported that a higher $\mathrm{Ar} / \mathrm{CH}_{4}$ ratio leads to a higher metallic composition or a lower carbon composition (Wu and Ting 2002; Nakao 2009). Therefore, it is believed that a sufficient amount of metallic constituents is required to allow the metal to form crystalline structure. The $\mathrm{Ar} / \mathrm{CH}_{4}$ ratio also affects the surface morphology of the Me-DLC thin films.

The optimum pressure and $\mathrm{Ar} / \mathrm{CH}_{4}$ ratio for the synthesis of Ag-DLC were selected as 30 mTorr and 10/90 ratio, respectively for obtaining a uniform colour of the film and avoiding of target poisoning. Variation in Ag content was achieved by varying the magnetron current (table 1). Figure 3 indicates the effect of d.c. current on deposition rate and $\mathrm{Ag}$ content in the DLC for 30 mTorr working pressure and $10 \%$ methane flow. As seen in figure 3, the deposition rate increased abruptly up to $80 \mathrm{~mA}$. After this current, the deposition rate was almost stable then it increased slowly with an increase in d.c. current. However, Ag content in the DLC increased almost linearly with an increase in d.c. current.

Table 1. Variation of film thickness, deposition rate and Ag content of Ag-DLC thin films with gas ratio and d.c. power and working pressure for $-1000 \mathrm{~V}$ bias voltage.

\begin{tabular}{lcccccr}
\hline Samples & $\begin{array}{c}\text { Working pressure } \\
\text { (mTorr) }\end{array}$ & $\begin{array}{c}\mathrm{CH}_{4} / \mathrm{Ar} \\
\text { ratio }\end{array}$ & $\begin{array}{c}\text { d.c. Power to } \\
\text { target }(\mathrm{mA})\end{array}$ & $\begin{array}{c}\text { Film thickness } \\
(\mathrm{nm})\end{array}$ & $\begin{array}{c}\text { Deposition rate } \\
(\mathrm{nm} / \mathrm{min})\end{array}$ & $\begin{array}{c}\text { Ag content } \\
(\text { at } \%)\end{array}$ \\
\hline DLC & 40 & $83 / 17$ & - & 7806 & 6.5 & - \\
Ag-DLC40-1 & 40 & $30 / 70$ & 100 & $490 \pm 4 \cdot 2$ & $16 \cdot 33$ & $0 \cdot 5 \pm 0 \cdot 05$ \\
Ag-DLC40-2 & 40 & $20 / 80$ & 100 & $435 \pm 5 \cdot 3$ & $14 \cdot 5$ & $0 \cdot 5 \pm 0 \cdot 04$ \\
Ag-DLC40-3 & 40 & $10 / 90$ & 100 & $60 \pm 2 \cdot 2$ & 2 & $0 \cdot 5 \pm 0 \cdot 06$ \\
Ag-DLC30-1 & 30 & $30 / 70$ & 100 & $340 \pm 6 \cdot 3$ & $11 \cdot 33$ & $1 \pm 0 \cdot 19$ \\
Ag-DLC30-2 & 30 & $20 / 80$ & 100 & $305 \pm 3 \cdot 6$ & $10 \cdot 17$ & $0 \cdot 8 \pm 0 \cdot 25$ \\
Ag-DLC30-3 & 30 & $15 / 85$ & 100 & $180 \pm 4 \cdot 3$ & 6 & $2 \pm 0 \cdot 31$ \\
Ag-DLC30-4 & 30 & $10 / 90$ & 100 & $160 \pm 2 \cdot 3$ & $5 \cdot 33$ & $8 \cdot 6 \pm 0 \cdot 37$ \\
Ag-DLC30-5 & 30 & $10 / 90$ & 50 & $100 \pm 3 \cdot 4$ & $1 \cdot 66$ & $2 \cdot 4 \pm 0 \cdot 45$ \\
Ag-DLC30-6 & 30 & $10 / 90$ & 70 & $105 \pm 4 \cdot 6$ & $1 \cdot 75$ & $2 \cdot 16 \pm 0 \cdot 48$ \\
Ag-DLC30-7 & 30 & $10 / 90$ & 80 & $215 \pm 6 \cdot 7$ & $3 \cdot 58$ & $3 \pm 0 \cdot 42$ \\
Ag-DLC30-8 & 30 & $10 / 90$ & 85 & $223 \pm 5 \cdot 3$ & $3 \cdot 72$ & $3 \cdot 23 \pm 0 \cdot 47$ \\
Ag-DLC30-9 & 30 & $10 / 90$ & 90 & $214 \pm 4 \cdot 6$ & $3 \cdot 56$ & $3 \cdot 7 \pm 0 \cdot 45$ \\
Ag-DLC30-10 & 30 & $10 / 90$ & 95 & $226 \pm 6 \cdot 7$ & $3 \cdot 76$ & $5,7 \pm 0 \cdot 29$ \\
Ag-DLC30-11 & 30 & $10 / 90$ & 100 & $253 \pm 5 \cdot 5$ & $4 \cdot 22$ & $8 \cdot 3 \pm 0 \cdot 46$ \\
Ag-DLC20-1 & 20 & $30 / 70$ & 100 & $275 \pm 7 \cdot 8$ & $9 \cdot 16$ & $0 \cdot 8 \pm 0 \cdot 1$ \\
Ag-DLC20-2 & 20 & $20 / 80$ & 100 & $104 \pm 6 \cdot 8$ & $3 \cdot 47$ & $1 \cdot 5 \pm 0 \cdot 15$ \\
Ag-DLC20-3 & 20 & $15 / 85$ & 100 & $220 \pm 6 \cdot 3$ & $3 \cdot 66$ & $10 \cdot 28 \pm 0 \cdot 55$ \\
Ag-DLC20-4 & 20 & $10 / 90$ & 100 & $124 \pm 5 \cdot 8$ & $4 \cdot 13$ & $13 \cdot 7 \pm 0 \cdot 58$ \\
\hline
\end{tabular}




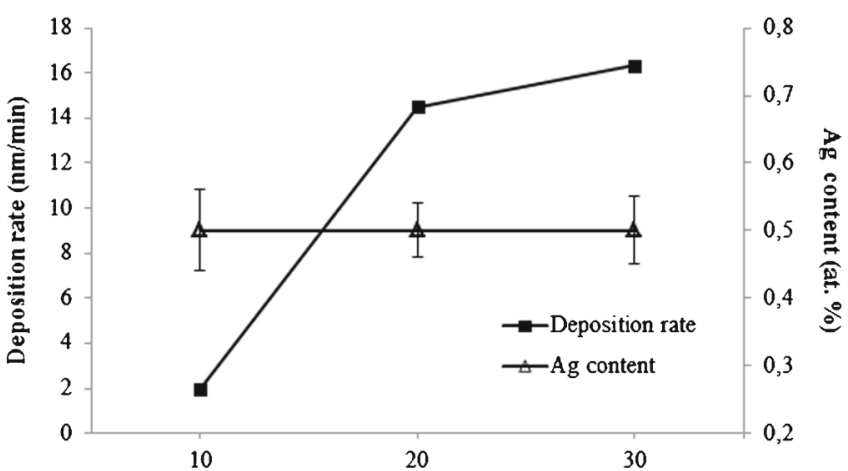

(a)

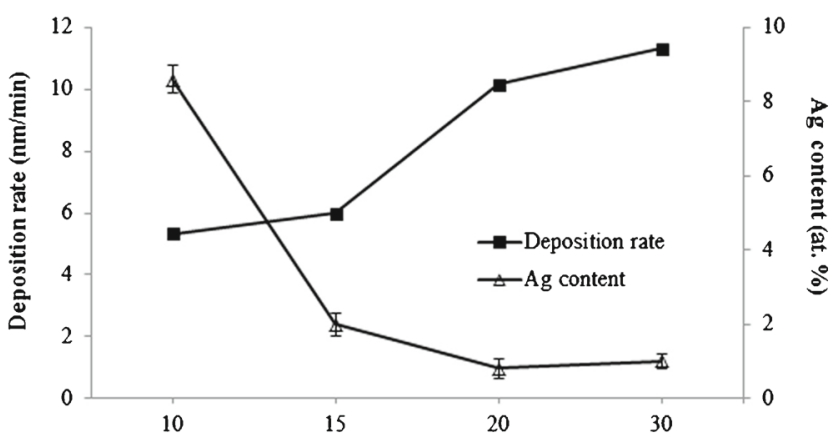

(b)

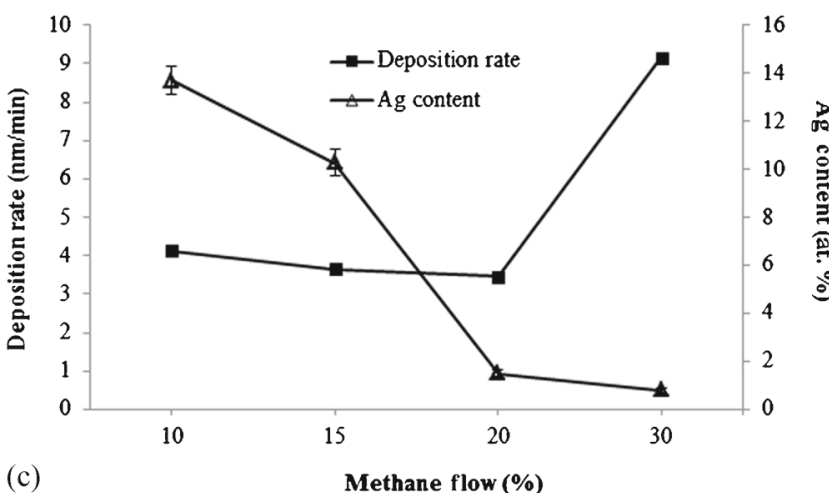

Figure 2. Effect of methane flow in the gas mixture composed of Ar and methane on deposition rate and Ag content of Ag-DLC films at bias voltage of $-1000 \mathrm{~V}$ for (a) 40 mTorr, (b) 30 mTorr and (c) 20 mTorr working pressure.

Figure 4(a) and (b) indicates the deposition rate and $\mathrm{Ag}$ content changes in the DLC films as a function of working pressure for $10 \%, 20 \%$ and $30 \%$ methane flows. As the working pressure increased, the deposition rate of Ag-DLC also increased. However, as seen in figure 4(a), the deposition rate did not have the same trend for $10 \%$ methane flow. This can be attributed to a problem for 40 mTorr. Choi et al (2008a, b) found that the deposition rate of DLC coatings linearly increased with increasing deposition pressure. Additionally, it is reported that radical species are increased with increasing pressure. This suggests that the plasma density is increased so that the ion flux is also increased in amount at

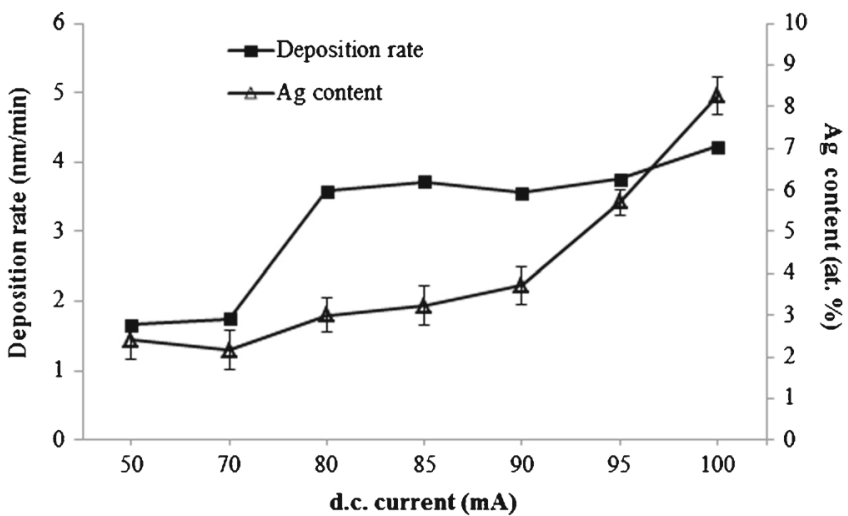

Figure 3. Effect of d.c. current on the deposition rate and Ag content in the Ag-DLC films for 30 mTorr working pressure and $10 \%$ methane flow.

(a)

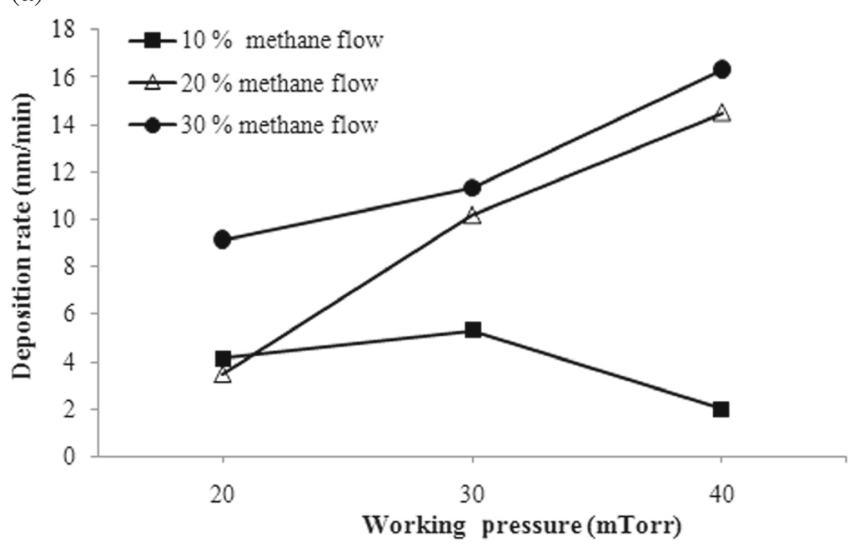

(b)

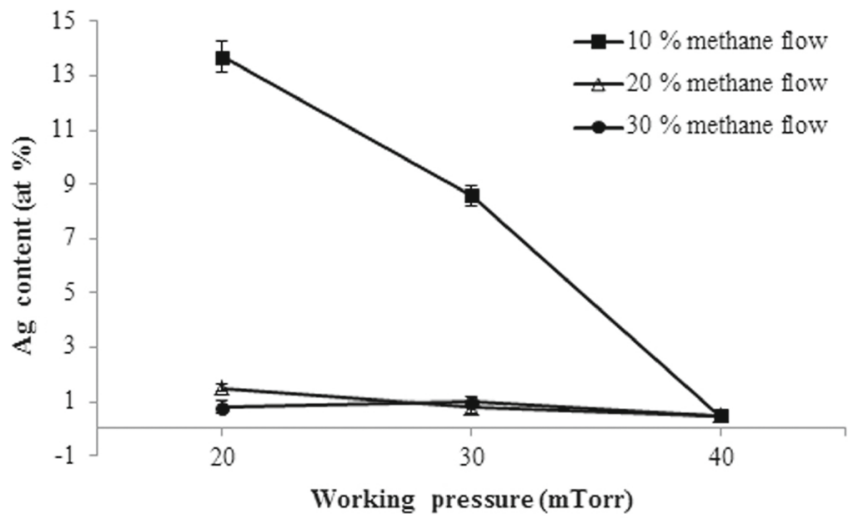

Figure 4. (a) Deposition rate and (b) Ag content variation in the a-C:H films as a function of working pressure for $10 \%, 20 \%$ and $30 \%$ methane flows.

the same time. Therefore, it is reasonable that the deposition rate is increased according to the increase of pressure. Furthermore, Gupta et al (2007) reported that the deposition rate increased at higher pressures due to larger hydrocarbon flux reaching the substrate surface. Ag content of Ag-DLC films decreased with an increase in methane flow as shown 


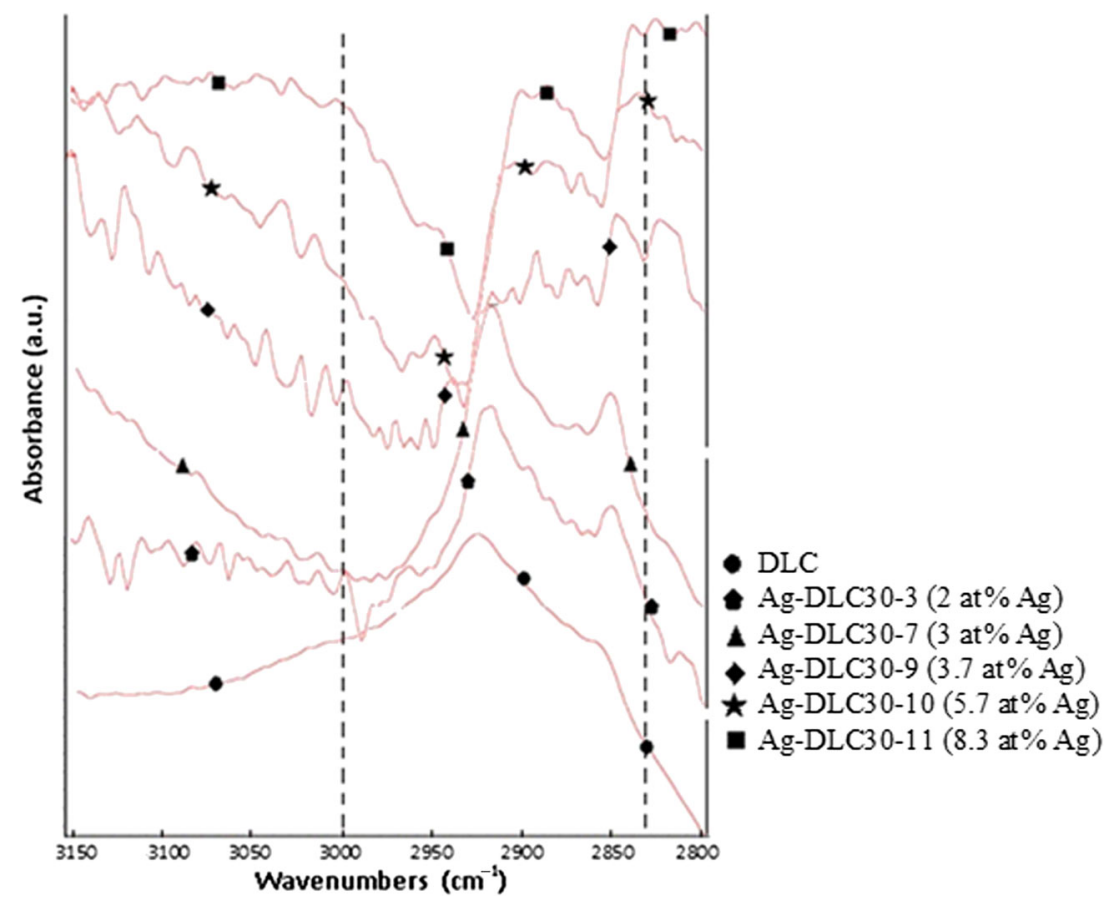

Figure 5. Comparison of FTIR spectra obtained from the DLC and Ag-DLC thin films.

in figure 4(b). The highest $\mathrm{Ag}$ content was observed for $10 \%$ methane flow due to the fact that a significant poisoning of the target was caused by the high flux of carbon ions for $20 \%$ and $30 \%$ methane flow.

\subsection{FTIR and HRTEM analysis of Ag-DLC thin films}

FTIR is a widely used technique to characterize $\mathrm{C}-\mathrm{H}$ bonding in hydrogenated DLC $(\mathrm{a}-\mathrm{C}: \mathrm{H})$ films. Bonding properties of hydrogenated DLC films can be changed by introducing the second phase such as Ag. FTIR spectrum analysis was used to investigate the change and the presence of $s p^{2}$ and $s p^{3}$ hybridization in the atomic bonding structure between carbon and hydrogen in the hydrogenated DLC film. The samples, DLC, Ag-DLC30-3 (2 at\% Ag), Ag-DLC30-7 (3 at\% Ag), Ag-DLC30-9 (3.7 at\% Ag), Ag-DLC30-10 (5.7 at\% Ag), Ag-DLC30-11 (8.3 at\% Ag) were selected for FTIR analysis. Figure 5 shows FTIR spectrums obtained from the DLC and Ag-DLC thin films. Generally, the vibration mode of the FTIR spectrum obtained from DLC films is classified into stretching-type and deformation-type bands. The vibration mode of the stretching-type carbon-hydrogen bond is observed in the range of $2850-3300 \mathrm{~cm}^{-1}$ and that of the deformation-type is observed in the range of 1300 $1700 \mathrm{~cm}^{-1}$. In our investigation, only the stretching-type vibration mode was observed for the DLC films. The $\mathrm{C}-\mathrm{H}$ stretching mode is revealed in the range of $2850-3300 \mathrm{~cm}^{-1}$ of the FTIR absorption spectrum. The $\mathrm{CH}_{3}$ asymmetric stretching vibration occurs at around $2975-2950 \mathrm{~cm}^{-1}$, whereas the absorption forms at about $2930 \mathrm{~cm}^{-1}$ for $\mathrm{CH}_{2}$. The $\mathrm{CH}_{3}$ symmetric vibration and the $\mathrm{CH}_{2}$ absorption occur in the ranges of $2865-2885$ and $2870-2840 \mathrm{~cm}^{-1}$, respectively (Heitz et al 1998). As seen in figure 5, after wavenumber of $2950 \mathrm{~cm}^{-1}$, absorption peak positions shifted to lower wavenumbers with an increase in Ag content in the DLC. Paul et al (2009) reported that by introducing Ag in DLC, the peak related to $\mathrm{Ag}-\mathrm{H}$ bonds became broad and shifted to a lower wavenumber. Furthermore, Hussain and Pal (2007) also indicated that the FTIR spectrum for DLC got significantly modulated by the incorporation of nanocrystalline $\mathrm{Ag}-\mathrm{Cu}$.

Deconvoluted FTIR spectrums of $\mathrm{C}-\mathrm{H}$ stretch region and the various bonding states of the $\mathrm{C}-\mathrm{H}$ stretching (as a table) in the DLC films are shown in figure $6(\mathrm{a}-\mathrm{c})$. The relative amount of each bonding type was obtained by estimating the area under each peak. As seen in figure $6(\mathrm{a}-\mathrm{c})$, by introducing $\mathrm{Ag}$ in the DLC, the shoulders at $\sim 2800-2850 \mathrm{~cm}^{-1}$ and $\sim 2970-3150 \mathrm{~cm}^{-1}$, which were arisen due to $s p^{3}-\mathrm{CH}$ symmetric and $s p^{2}-\mathrm{CH}$ olefinic stretching vibrations, which were arisen, became prominent, respectively. The obvious absorption peaks at $2830-2920$ and $2960-2980 \mathrm{~cm}^{-1}$ are due to the hydrogen atom in the $\mathrm{CH}_{2}$ (sym-asym) $/ \mathrm{CH}_{3}$ (sym) stretching bands, all bonded to $s p^{3}$-type carbon. The peaks located at $2950 \mathrm{~cm}^{-1}$ and in the range of 3000 $3110 \mathrm{~cm}^{-1}$ may be assigned to $s p^{2}-\mathrm{CH}_{2}$ (sym) and $s p^{2}$ $\mathrm{CH}$ (olef./arom.) bonding stretching modes (Mutsukura et al 1992; Heitz et al 1998; Son et al 2001). Teii (1998) observed relative increases in the intensity of the $s p^{2}$ bond at $3000-3150 \mathrm{~cm}^{-1}$. From these results, it can be said that the bonding structures between carbon and hydrogen in the Ag-DLC films consist of $s p^{3}$ and $s p^{2}$ bonds. Figure 7 shows variation of $s p^{3} /\left(s p^{2}+s p^{3}\right)$ ratio based on $\mathrm{C}-\mathrm{H}$ bonds with 

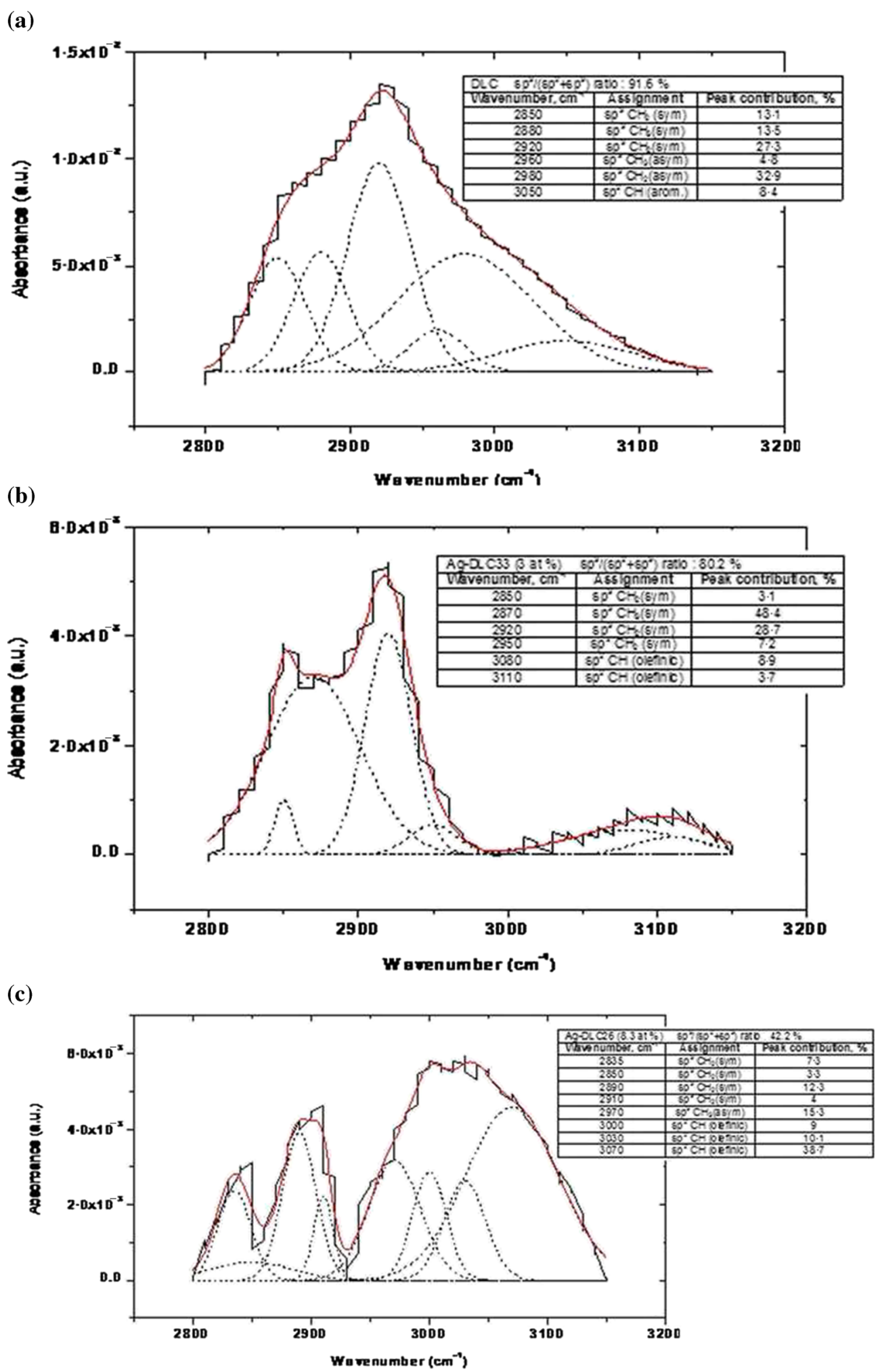

Figure 6. Deconvolution of the $\mathrm{C}-\mathrm{H}$ stretch and FTIR vibrational mode assignment in the $\mathrm{C}-\mathrm{H}$ stretch region (as a table) for (a) DLC, (b) Ag-DLC30-7 containing 3 at\% Ag and (c) Ag-DLC30-11 containing $8 \cdot 3$ at $\%$ Ag thin films.

$\mathrm{Ag}$ content in the DLC films. It can be seen in figure 7 that, as the Ag content in the DLC increased, the $s p^{3}$ bond decreased. The ratios of $s p^{3} /\left(s p^{2}+s p^{3}\right)$ were obtained from the deconvoluted spectra based on the areas under the $s p^{2}$ and $s p^{3}$ peaks. The ratio of undoped DLC film was 0.916, whereas $s p^{3} /\left(s p^{2}+s p^{3}\right)$ ratios of Ag-DLC30-7 (3 at\%) 


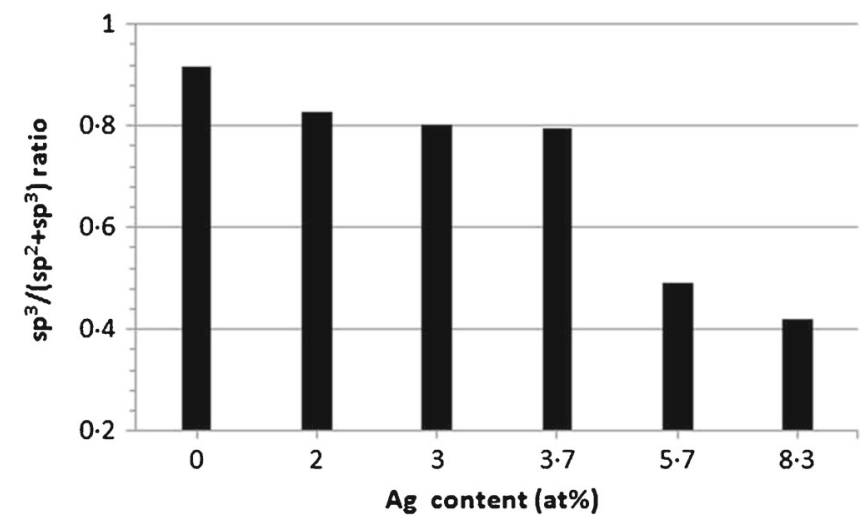

Figure 7. Variation of $s p^{3} /\left(s p^{2}+s p^{3}\right)$ ratio based on $\mathrm{C}-\mathrm{H}$ bonds with $\mathrm{Ag}$ content in the DLC films.
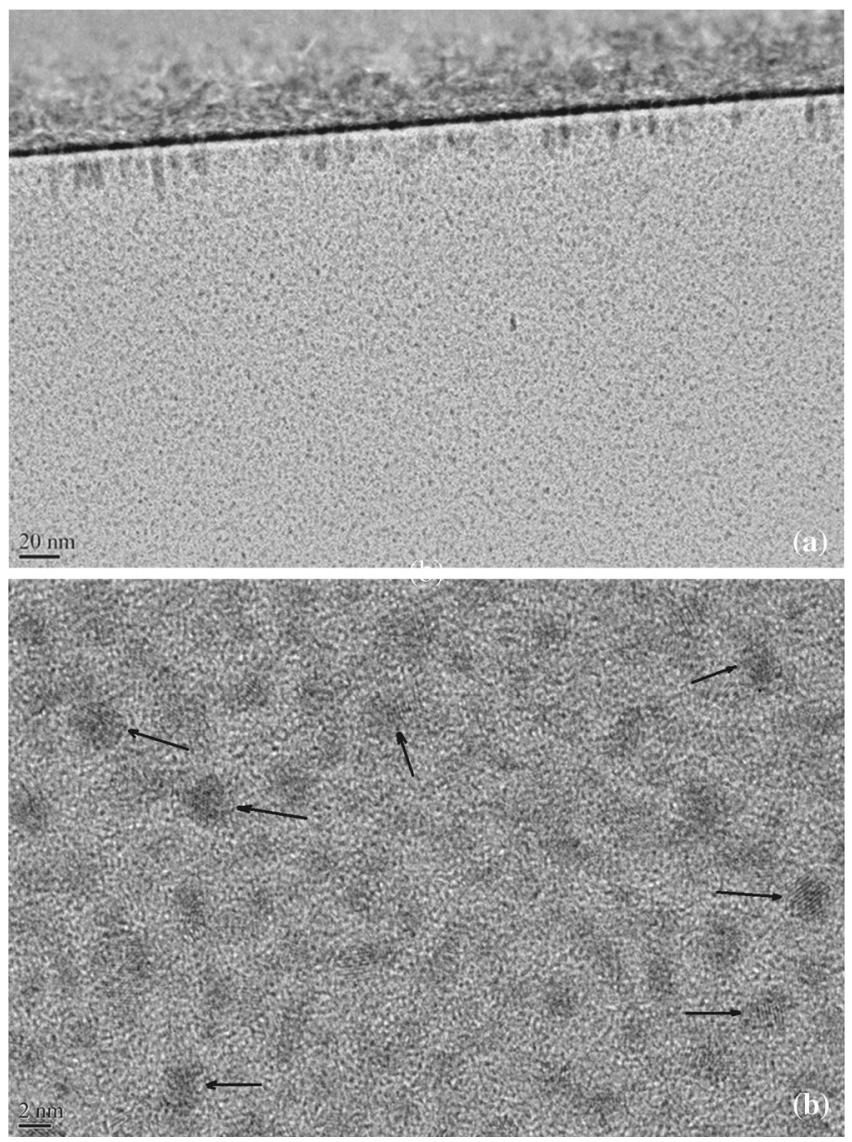

Figure 8. HRTEM images of (a) cross-sectioned Ag-DLC30-7 film containing 3 at $\% \mathrm{Ag}$ (b) nanocrystalline Ag grains under higher magnification of in (a). The arrows show crystalline Ag particles.

and Ag-DLC30-11 (8.3 at\%) films were 0.802 and 0.422, respectively. Paul et al (2009) observed that $s p^{2} / s p^{3}$ ratio derived from deconvoluted FTIR spectra increased from 0.03 for the film lesser $\mathrm{Ag}$ content to 0.21 for films with higher $\mathrm{Ag}$ content in the DLC matrix. It may thus be inferred that the Ag-DLC films became $s p^{2}$ rich with increasing incorporation of silver nano-crystallites. Similar trends have been observed for other metal-doped DLC films (Klages and Memming 1989; Corbella et al 2004; Pandey and Hussain 2011).
Figure 8( $\mathrm{a}$ and $\mathrm{b})$ shows HRTEM cross-section microstructure of DLC film containing 3 at\% Ag. HRTEM analysis in figure 8a has revealed that silver nanoparticles were distributed uniformly throughout the film. The darker spots (indicated by arrows in figure 8b) correspond to the metallic Ag region, while the brighter region corresponds to the amorphous carbon matrix. As seen in figure 8(b), Ag-incorporated DLC film showed amorphous carbon structure and also partially segregated and formed crystalline Ag particles with a size in the range of 2-4 $\mathrm{nm}$. It can be clearly seen that there are ordered areas with different orientation of crystalline planes within the dark spots with nearly spherical shape.

\section{Conclusions}

A hybrid deposition system composed of d.c. plasma enhanced chemical vapour deposition (PECVD) and d.c. magnetron sputtering was successfully employed to deposit Ag-incorporated hydrogenated-DLC films. It was observed that the working pressure and $\mathrm{CH}_{4} / \mathrm{Ar}$ ratio played a very important role in controlling the Ag content in DLC. When the Ar concentration was less than $90 \%$, the incorporation of $\mathrm{Ag}$ in the film was detected a little probably due to a significant poisoning of the target. For this study, the optimum pressure and $\mathrm{Ar} / \mathrm{CH}_{4}$ ratio for the synthesis of $\mathrm{Ag}$-DLC were 30 mTorr and 10/90, respectively, because of for obtaining a uniform film colour and avoiding of target poisoning.

FTIR spectra indicated that The $\mathrm{C}-\mathrm{H}$ stretching mode was revealed in the range of $2850-3100 \mathrm{~cm}^{-1}$. FTIR results showed that the bonding structure between carbon and hydrogen in the DLC film consisted mostly of $s p^{3}$ and a few $s p^{2}$ bonds. As the Ag content in the DLC increased, the $s p^{3}$ bond decreased. HRTEM observation showed that the films contained uniformly distributed Ag nanoparticles in the range of 2-4 $\mathrm{nm}$ size in an amorphous DLC matrix.

\section{Acknowledgement}

Dr S Taktak is grateful to the Scientific and Technological Research Council of Turkey (TUBITAK) for the award of the 2219 International Post Doctoral Research Fellowship.

\section{References}

Ahmed S F, Moon M W and Lee K R 2008 Appl. Phys. Lett. 92 193502

Ahmed S F, Moon M W and Lee K R 2009 Thin Solid Films 517 4035

Baba K, Hatada R, Flege S, Ensinger W, Shibata Y, Nakashima J, Sawase T and Morimura T 2013 Vacuum 89179

Bewilogua K, Cooper C V, Specht C, Schröder J, Wittorf R and Grischke M 2000 Surf. Coat. Technol. 132275

Bull S J 1995 Diam. Relat. Mater. 4827

Choi H W, Choi J H, Lee K R, Ahn J P and Oh K H 2007 Thin Solid Films $\mathbf{5 1 6} 248$ 
Choi H W, Dauskardt R H, Lee S C, Lee K R and Oh K H 2008a Diam. Relat. Mater. 17252

Choi J, Nakao S, Ikeyamab M and Kato T 2008b Surf. Interface Anal. $\mathbf{4 0} 806$

Corbella C, Vives M, Pinyol A, Bertan E, Cana C 1, Polo M C and Andujar J L 2004 Surf. Coat. Technol. 1777-1778 409

Erdemir A and Donnet C 2006 J. Phys. D: Appl. Phys. 39 R311

Gupta P, Singh V and Meletis E I 2007 Tribol. Int. 371019

Heitz T, Drevillon B, Godet C and Bouree J E 1998 Phys. Rev. B 58 13957

Hussain S and Pal A K 2006 Bull. Mater. Sci. 29553

Hussain S and Pal A K 2007 Appl. Surf. Sci. 2533649

Klages C P and Memming R 1989 Mater. Sci. Forum 52-53 609

Kwok S C H, Zhang W, Wan G J, McKenzie D R, Bilek M M M and Chu P K 2007 Diam. Relat. Mater. 161353

Lan W C, Ou S F, Lin M H, Ou K L and Tsai M Y 2013 Ceram. Int. 394099

Lee H L and Ting J M 2003 Mater. Chem. Phys. 82567

Liu Y and Meletis E I 1997 J. Mater. Sci. 323491

Manninen N K, Ribeiro F, Escudeiro A, Polcar T, Carvalho S and Cavaleiro A 2013 Surf. Coat. Technol. 232440
Marciano F R, Bonetti L F, Pessoa R S, Marcuzzo J S, Massi M, Santos L V and Trava-Airoldi V J 2008 Diam. Relat. Mater. 17 1674

Mutsukura N, Inoue S and Machi Y 1992 J. Appl. Phys. 7243

Nakao S 2009 Nucl. Instrum. Meth. B 2671684

Pandey B and Hussain S 2011 J. Phys. Chem. Solids 721111

Paul R, Gayen R N, Hussain S, Khanna V, Bhar R and Pal A K 2009 Eur. Phys. J. Appl. Phys. 4710502

Pauleau Y and Thiery F 2004 Surf. Coat. Technol. 180-181 313

Robertson J 1992 Surf. Coat. Technol. 50185

Son Y H, Jung W C and Jeong J I 2001 J. Korean Phys. Soc. 39 713

Takeno T, Saito H, Goto M, Fontaine J, Miki H, Belin M, Tagagi T and Adachi K 2013 Diam. Relat. Mater. 3920

Teii K 1998 Thin Solid Films 333103

Wang J S, Sugimura Y, Evans A G and Tredway W K 1998 Thin Solid Films 325163

Wang Y, Ye Y, Li H, Ji L, Wang Y, Liu X, Chen J and Zhou H 2011 Surf. Coat Technol. 2054577

Wu W Y and Ting J M 2002 Thin Solid Films 420-421 166

Yu X, Hua M and Wang C 2009 J. Nanosci. Nanotechnol. 96366 